FLAVIA SOLDANO

\title{
UN PROBLEMA DE FRONTERA Marcos 7,24-30
}

\section{Resumen}

¿Cómo se articula el milagro en Mc 7,24-30? ¿Quién lo realiza? ¿Qué papel juega la extranjeridad en la mujer sirofenicia? Abordaré el análisis del texto presentando la curación como operación de lenguaje que perfora el rígido sistema de creencias en el que se basan algunas concepciones de frontera. Me guía un punto de vista discursivo y semántico para proponer que estamos frente a una "curación de traslado" y un "milagro invertido". Este camino no implica la hermenéutica teológica, sino el trabajo con los elementos de la lengua en cuanto organización de las relaciones significantes u orden simbólico.

Palabras clave: Evangelio de Marcos. Mujer sirofenicia. Análisis del discurso. Simbolos.

Hay dos textos protagonizados por mujeres que me gusta poner en serie. Los llamo "milagros raros". Raros en el sentido de que lo que lleva a la curación es enigmático.

Uno de los textos es la curación de la hemorroísa en Mc 5,24-34; Mt 9,20-42 y Lc 8,43-4. El otro texto es el de la mujer siriofenicia en Mc 7,2430 y Mt 15,21-28. En ambos, la curación se articula entre una posición discursiva que podemos llamar "de lo particular" como lo contrapuesto al discurso "de lo universal".

Abordaré aquí solo el análisis del texto marcano, desde un punto de vista discursivo y semántico, proponiendo que estamos frente a una "curación de traslado" y un "milagro invertido".

Y aquí quiero hacer una salvedad, porque el punto de vista que menciono no implica la interpretación teológica, sino que trabajaré con los elementos del discurso en cuanto organización de las relaciones significantes u orden simbólico. 
Cuando digo simbólico me estoy refiriendo al campo del lenguaje, a la dimensión lingüística del discurso en cuanto lazo que arma el vínculo social. El discurso opera así como un pacto que permite que cada uno se ubique respecto de otro, y en esta articulación se enuncian las palabras.

Este punto de vista corre el acento del sujeto como agente del discurso para ubicarlo como resultante de su posición en el entramado discursivo. El lenguaje nos determina, tejiéndonos en la textura de lo simbólico. Hablar, entonces, es un asunto de posiciones dependientes de ciertas reglas. De este modo hay más en la palabra que lo que la palabra quiere decir.

La psicoanalista Marta Gerez Ambertín lo ejemplifica del siguiente modo:

Si se toma como ejemplo el juego de ajedrez, vemos que allí es en función de ciertas reglas convencionales, que operan como código, como serán posibles las jugadas. Pero en cada jugada es el sujeto el que queda ubicado en cierta posición con relación a la jugada del otro?

\section{Relaciones significantes en el texto}

1. La idea de frontera como elemento simbólico es uno de los organizadores de las relaciones significantes del texto.

1.1. La metáfora es una relación de frontera: en tanto operación discursiva que implica una sustitución y traslado, cuyo resultado es un plus o nuevo sentido que nos ubica en lo simbólico. Recordemos que metáfora se compone de meta (más allá) y pherein (trasladar).

La idea de frontera la ubico en este marco, como la forma que toma el modo del vínculo en esta narración. Es decir, que el texto de Mc 7,24-30 se articula discursivamente en relación con la frontera. El modo de esta articulación es metafórico, en cuanto encuentro sustituciones y traslados que dan como resultado un nuevo sentido.

El historiador británico Arnold Toynbee, en su trabajo Estudio sobre la historia, plantea la tensión entre los conceptos de limes y limen como dos formas de contacto fronterizo en la antigüedad ${ }^{2}$.

Para este autor, el limes se refiere a la línea longitudinal militar y aduanera con que los romanos intentaban cercar y separar al mundo bárbaro.

1 M. Gerez Ambertín, “Las claves del sujeto en Lacan”, Psico-Logos (6 abril 1996), en https://sites.google.com/a/fundpsicsigmundfreud.org/.../las-claves-del-sujeto-en-lacan [consulta: 3/2/2016].

2 Cf. K. G. NwelHed, Fronteras y su límite en su marco mundial, una introducción a la fronterología, Caracas 1992, 120. 
El limen es una zona amortiguadora de transición propia de la concepción de la polis griega.

A pesar del limes, intento romano de frenar y separarse de los bárbaros, el limen se produjo favoreciendo a los últimos. El intercambio de culturas en la porosidad de la zona fronteriza fue inevitable.

Cuando la frontera, como elemento discursivo, se ubica en relación con el otro como un muro que intenta obturar el encuentro entre dos universos de sentido, se presenta como limes. Sin embargo, el limen, como otra posición, da cuenta de que otra articulación del mensaje es posible.

Siguiendo esta línea es posible pensar la frontera también como un sistema de creencias que, como todo sistema lingüístico, presenta puntos de quiebra o hendiduras. Ubicar estas "fallas" o "pequeñas aperturas" del sistema permite el cambio, la interacción con otros sistemas, la intersección con otros discursos, las sustituciones, la producción de nuevos sentidos, la metáfora como pliegue de la narración.

\section{Análisis del texto}

La articulación de la relación de frontera se forja con algunas variables. El marco particular de esta narración está dado por tres factores:

1. El cruce geográfico del límite.

2. El no poder esconderse o quedar al descubierto.

3. La destinataria de la curación no participa -de palabra o forma presencial- de la escena. Solo en el final la encontramos acostada y curada.

Jesús se traslada a tierra extranjera, donde se integran etnias y credos, y conviven judíos con las comunidades griegas, romanas y siria.

Allí intenta ocultarse, pero no lo logra.

${ }^{24}$ Levantándose de allí se fue a la región de Tiro y de Sidón. Entró en una casa, y no quería que nadie lo supiera; pero no pudo esconderse ${ }^{3}$.

Jesús se levanta para bordear la otredad. Se traslada al cruzar la frontera e intenta esconderse en una casa, pero no lo logra: queda al descubierto. Pero este "quedar al descubierto" no es solo una inferencia narrativa, sino que también se articula en el discurso como los ya mencionados puntos de quiebra o hendiduras del sistema de creencias. La hiancia, la apertura por donde filtra el limen, ha comenzado su función. En este texto, cruzar la frontera ocasiona consecuencias.

3 Reina-Valera revisada, 1995; de aquí en más utilizaremos esta versión del texto bíblico. 
Inmediatamente aparece la mujer de origen griego:

${ }^{25}$ Una mujer, cuya hija tenía un espíritu impuro, luego que oyó de él vino y se postró a sus pies.

La mujer va hacia Jesús, quien había quedado al descubierto.

${ }^{26}$ La mujer era griega, sirofenicia de origen, y le rogaba que echara fuera de su hija al demonio.

¿Qué nos indica el relator con la mujer como griega sirofenicia por nacimiento? Se pone de manifiesto el énfasis en señalar en ella la diferencia, la frontera social, mientras que es Jesús quien está en tierra extranjera. Sin embargo, se deja en claro que la mujer ubicada en la zona de Tiro y Sidón no pertenece al mundo judío de la diáspora que habitaba allí. Se la ubica por fuera del conjunto, generando así una nueva frontera.

El narrador también menciona en 7,25 una pequeña hija de la mujer, tó thygátrion, que tenía un espíritu impuro, pneuma akátharton ${ }^{4}$.

A continuación, en 7,26, el relator, utilizando el "discurso indirecto" de la mujer, menciona la palabra daimónion. Si bien estas palabras parecen tener el mismo significado, provienen de diferentes campos semánticos y culturales.

Pneuma akátharton pertenece al campo semántico hebreo afectado por el exilio babilónico. En cambio, daimónion señala la influencia griega en el mundo neotestamentario ${ }^{5}$.

La frontera también aquí es semántica. El narrador utiliza una palabra de contexto hebreo cuando describe la situación (oración principal), y luego, al nombrar el origen de la mujer y utilizar el discurso indirecto de ella, usa la palabra daimónion.

Se pone en juego una diferencia que deja en claro que hay una disimilitud cultural. Esta diferencia nos prepara para lo que viene:

${ }^{27}$ Pero Jesús le dijo: “Deja primero que se sacien los hijos, porque no está bien tomar el pan de los hijos y echarlo a los perros".

La frase comienza con un tono marcado por el imperativo. Luego resaltan las palabras "hijos" y "perros":

tà tékna, ton téknon ${ }^{6}$

tois kynariois

${ }^{4}$ Todas las palabras en griego están extraídas del siguiente texto: E. NESTLE B. Aland - K. Aland - J. Karavidopoulos - C. M. Martini - B. Metzger, The Greek New Testament, Stuttgart 271993.

${ }^{5}$ H. G. LIDELL - R. SCOTt, A Greek-English Lexicon, Oxford ${ }^{9} 1961$ (orig. de 1843).

$6 \mathrm{lb}$. 
Se produce la primera sustitución:

1. Tois kynaríois sustituye a tó thygátrion.

2. Tois kynaríois queda en relación de exclusión con tà tékna.

Se plantea una división tajante, un limes entre tà tékna y tois kynariois.

La palabra que se traduce por hijos, tà tékna, se refiere a niños, pero también al campo semántico de las genealogías. En plural se refiere a quienes comparten la fe en un importante antepasado. Como hebraísmo denota a los que pertenecen a la misma ciudad ${ }^{7}$.

En Mt 15,24-56, esta frase se reescribe duplicando la exclusión:

${ }^{24}$ Él, respondiendo, dijo: "No soy enviado sino a las ovejas perdidas de la casa de Israel".

${ }^{25}$ Entonces ella vino y se postró ante él, diciendo: “¡Señor, socórreme!”

${ }^{26}$ Respondiendo él, dijo: "No está bien tomar el pan de los hijos y echarlo a los perros".

En Mc 7,27 se construye la exclusión, el limes, con el uso del adverbio proton sumado al conector causativo ou gar (... primero... porque no...).

Veamos la respuesta de la mujer:

${ }^{28}$ Respondió ella y le dijo: “Sí, Señor; pero también los perros, debajo de la mesa, comen de las migajas de los hijos".

Otra cuestión que cambia en este texto es la palabra "hijos". Se produce una nueva sustitución: ton paidíon reemplaza a tà tékna.

El nominativo plural tà paidía es un diminutivo, niños pequeños. También en sentido figurado puede ser hijos de Dios o una expresión de afecto paternal ${ }^{8}$. Este significante pertenece al mismo contexto semántico que daimónion.

Es interesante la operación que produce la frase de la mujer. Si en 7,27 Jesús separa, en 7,28 ella incluye:

1. Él plantea una opción excuyente: solo para los suyos es el pan de la mesa. El sentido de la frase de Jesús es rígido: la curación es solo para tá tékna (los verdaderos hijos), ou gar (porque no) es para los otros.

2. Y a ese punto excluyente es que la mujer responde: sí, pero además hay otra opción. Y en esa opción los perritos, que antes estaban en dativo, son ahora sujeto de la frase. Son los que ejecutan la acción. Es decir, donde Jesús plantea el limes, la mujer introduce el limen.

Lo "descubierto" comienza a operar en el discurso. Lo cubierto, lo rígido del sistema de creencias, presenta porosidades:

7 J. Swanson, Diccionario de idiomas bíblicos: griego (Nuevo Testamento), ed. electrónica, 1997.

$8 \mathrm{lb}$. 
La mujer acepta el universal, dice: naí, Kyrie, "sí, Señor", pero al usar el adversativo kaí gar presenta otra opción: pero también los perros (los no tà tékna) pueden ser curados. Y luego se implica a través de un cambio semántico en otra sustitución:

1. En vez de tà tékna, ella introduce tà paidía (en su versión de genitivo: tón paidion). El sentido de la frase cambia al sustituir una palabra que marca un limes por otra que abre al limes. Tà paidía se refiere a niños, a los hijos propios, pero también son los hijos de Dios: un conjunto abierto9

Finalmente, Jesús habla directamente a la mujer para anunciarle que la curación ya se ha realizado.

${ }^{29}$ Entonces le dijo: "Por causa de esta palabra, vete; el demonio ha salido de tu hija".

El campo semántico que utiliza Jesús ahora es el de la mujer sirofenicia, griega de nacimiento: thygáter y daimónion.

Hay en este paso un cambio de enunciación que implica nuevas sustituciones:

1. Jesús ya no habla del despectivo tà kynária, sino que lo ha remplazado por "hija", thygáter (en declinación de genitivo singular thygatrós). Este significante retorna luego de haber sido sustituido. Y él lo menciona por primera vez.

En thygáter se sustituyen ahora tà tékna y tà kynária.

2. Del mismo modo sucede con daimónion, que ha sustituido al espíritu impuro, pneuma akátharton.

El daimónion se traslada, ha salido de la hija.

Jesús atribuye el plus de sentido que implica la curación no a la fe, sino a tòn lógon, la "palabra" de la mujer.

Y esta palabra es la que le ha señalado a Jesús lo descubierto en su discurso, que no existe el limes en cuanto absoluto. Y que el limen permite las sustituciones de sentido.

Como resultado se produce un traslado en la posición semántica de Jesús. Una metáfora cuyo plus de sentido es la curación de la hija.

Finalmente, la hija aparece en el relato:

${ }^{30}$ Cuando la mujer llegó a su casa, halló a la hija acostada en la cama, y que el demonio había salido de ella.

La mujer se traslada a su casa. Y, a diferencia del principio, donde la casa ha sido escondite inútil para el traslado de Jesús, aquí está la hija curada.

9 LIDELL - Scott, A Greek-English Lexicon. 
El texto comienza con Jesús levantándose y termina con la hija acostada. La hija no se traslada, está quieta, porque ha sido curada.

La curación entonces se articula como metáfora entre los diversos traslados que perforan la frontera. Y el milagro queda invertido, es el cambio que se produce en Jesús a causa de la posición particular de la mujer para hablar.

Flavia Soldano 